\title{
FACTORS AFFECTING THE FREQUENCY DISTRIBUTION OF CLAY MINERALS IN SOILS
} by

\author{
IsAaC BARShaD \\ Department of Soils and Plant Nutrition \\ University of California, Berkeley
}

\begin{abstract}
AN extensive survey of the clay minerals and the other mineral colloids of many soils led to the conclusions that the chemical environment that exists in a soil during its development determines the kind of clay minerals that are being formed and that the frequency distribution of the clay minerals and the other mineral colloids, exclusive of those inherited from the parent material, are determined by the chemical environment occurring during soil formation. Furthermore, the chemical environment also determines the nature and extent of the alteration that biotite and muscovite undergo during breakdown to colloidal dimensions.

Because the chemical environment of a soil is determined by the factors of soil formation, a good correlation exists between these factors and the frequency distribution of the clay minerals.

Any of the factors of soil formation that function to maintain a neutral or an alkaline environment and to accumulate $\mathrm{CaCO}_{3}$ also induce the formation and accumulation of montmorillonite--whether this formation is through synthesis or through the alteration of micas and vermiculites. Thus, highly basic parent materials, such as serpentines and periodotites, that tend to maintain a neutral to basic environment regardless of degree of leaching, induce montmorillonite formation. Also under low rainfall conditions montmorillonite always accumulates regardless of the nature of the parent materials. Furthermore, conditions that impose on the soil a base accumulating environment, such as poor drainage, high water table, or its position in the profile as deep horizons, also induce montmorillonite formation. If potassium is high in such an environment, the mica minerals are either synthesized or accumulated.

Any of the factors, however, that function to maintain a highly base-depleting environment, such as high rainfall, good drainage and a high permeability, or the position of a soil in the profile as surface horizons, are conducive to kaolinite and halloysite formation. Acidic parent materials with high permeability, such as pumice and volcanic ash, or very dense basic rocks, such as basalts that have an extremely low water holding capacity, are particularly responsive to kaolinite and halloysite formation even at moderate precipitation.

Any of the factors that function to maintain an intermediate environment, i.e. between a highly accumulating and a highly depleting one, induce the formation of vermiculite either by synthesis or by the alteration of the micas. Soils found presently in such environments have the broadest frequency distribution of clay minerals. This is believed to reflect an environment that has responded readily to change in the course of soil development, particularly with respect to changes in rainfall and temperature.
\end{abstract}

